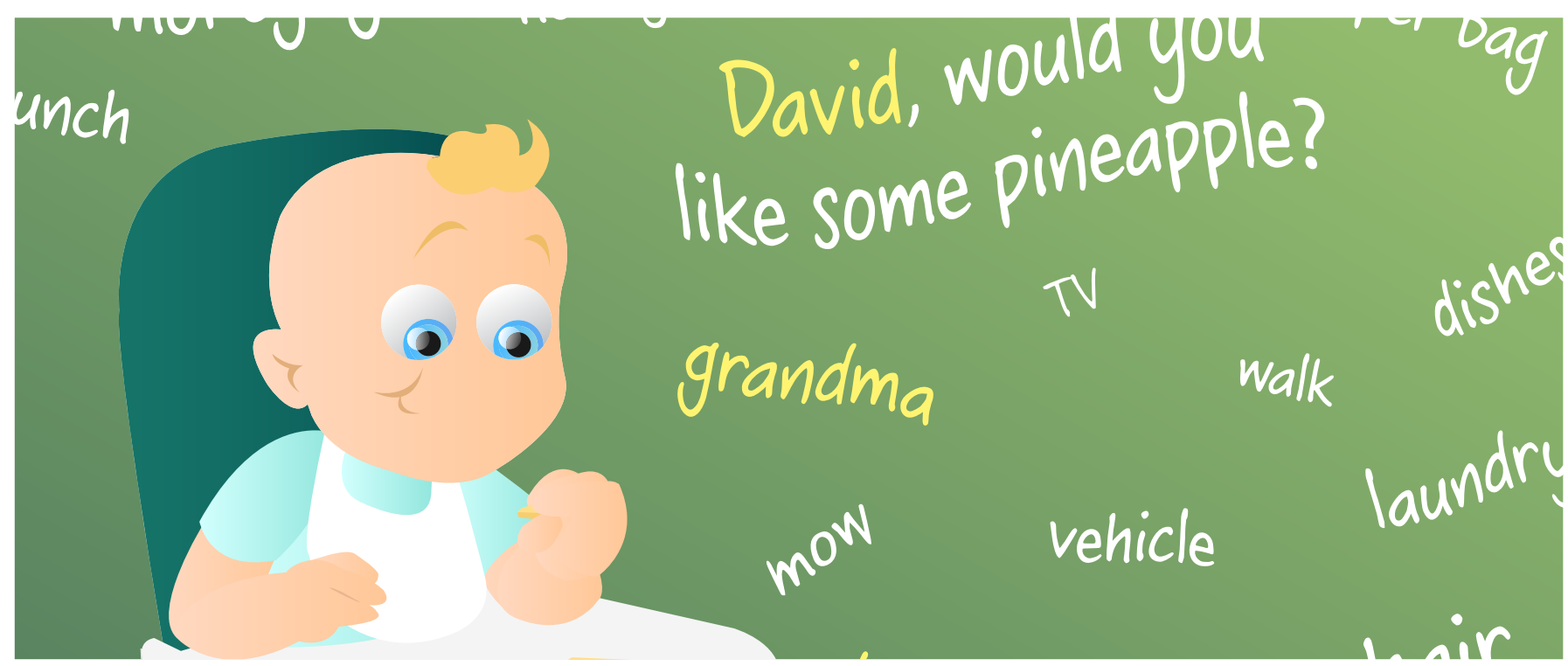

\title{
HOW DO LITTLE KIDS LEARN LANGUAGE?
}

\section{Casey Lew-Williams ${ }^{1 *}$ and Adriana Weisleder ${ }^{2}$}

${ }^{1}$ Princeton University, Princeton, NJ, United States, ${ }^{2}$ New York University School of Medicine, New York, NY, United States

\section{REVIEWED BY:}

NICK

12 YEARS OLD
Different kids grow up in different environments. Imagine Kid A: she gets to play and talk with her parents a lot, she has a yummy dinner every night with her family, she gets to travel on airplanes, and she has lots of books in her bedroom. Now imagine Kid B: his parents are really busy, he does not play or talk with grownups very much, he watches TV a lot, he does not get to eat much healthy food, and he almost always stays in his house. Kid A gets a lot of chances to have fun and learn, and Kid B gets fewer chances. Kid A gets to read about adventures all over the world, and Kid $B$ does not get as much practice with reading. Did you get a lot of chances to play, talk, and learn when you were little? Have you ever thought about how other kids' lives were different from yours? Have you ever thought about all the complicated stuff you learned, like language? There are lots of scientists who study how babies and little kids learn, and we want to tell you about some important research findings. After you finish reading, we hope you feel excited about how this science could help give every kid a fair chance to learn.

\section{YOU LEARNED A LOT, WITHOUT EVEN KNOWING IT!}

Babies look like little blobs who cannot do very much. They are little blobs! But scientists have shown that babies have an incredible ability to learn. In the 
first few years of life, we learn a lot of amazing information, usually without even knowing we are learning. Language is a perfect example of this. What language or languages did you learn as a little kid? We are guessing you know English, because you can read this sentence. Have you ever thought about how you learned all the bits and pieces of language? As a newborn baby, you knew almost nothing about sounds and words, but by the time you grow up, you might know as many as 50,000 or 100,000 words. You can do pretty impressive stuff. For example, you can probably fill in the missing word here: It's bedtime. Time to brush your

How did you do that? Could you explain to a friend or grownup how you were able to fill in the blank? It is incredible if you think about it. You just predicted the word teeth (or maybe hair). You predicted the future.

It is hard to figure out how little kids learn something as complicated as language. Do they copy their parents? Do they start making sounds until the right words come out? Do they find patterns and learn which sounds go together a lot, like $b-a-b-y$ ? Do they learn that different words match up with different things and use this to figure out what the words mean? Do they make guesses about what words come next and then learn from their mistakes? Do they just want to have fun with their moms, dads, brothers, and sisters, and this motivates them to learn language? Different scientists think learning happens in different ways. There are so many possibilities. While scientists love to disagree with each other, they generally agree that learning builds on itself over time. The first years of life matter a lot for our ability to learn later on and for our ability to do well in school. What's exciting is that language learning is still a big mystery, and scientists will have plenty of work to do in the coming decades (or even centuries)! One of the biggest challenges is figuring out how we can use the scientific method to study babies and language.

\section{HOW DO SCIENTISTS STUDY LEARNING?}

It is hard to study how babies learn, because they cannot tell us what they are thinking. So how do we know what babies know or what they can learn? There are many methods for studying learning and language, and these methods are used by scientists who study many different topics: psychology, neuroscience, education, linguistics, medicine, communication sciences, and public health (if you do not know what these words mean, feel free to email us: caseylw@princeton.edu and adriana.weisleder@gmail.com). We are going to describe two specific ways that scientists study babies. We hope you think these methods are interesting.

First, scientists use something called eye tracking. Starting when we are born, we can move our eyes. We look at things when we are interested, and we look away when we are bored. Scientists can use eye movements to understand 
what little kids know. For example, we sometimes ask little kids to look at a TV screen with two pictures on it, such as a ball and a cup. Then, kids hear a sentence like this: Do you see the ball? Using a fancy camera, we can see how quickly kids move their eyes to the ball. Scientists have learned that kids get faster and faster at moving their eyes to the right picture. Sometimes, little kids figure out which picture to look at just by hearing the beginning of the word (Look at the $b$-). We made a short video for you so that you can see how this works: https://youtu.be/CuLMn8uQxss.

Second, scientists ask parents to tell us what their kids know. For example, we sometimes give parents a list with hundreds of words on it and they put check marks next to the words their kids know. Do you think your parents could do this very well? Maybe, maybe not. It is hard for parents to remember all the words their kid has ever said. So, scientists also need to ask kids themselves. One way we do this is by asking kids to point to pictures while they hear different words. We ask kids about easy words that they have probably heard a lot and about harder words that are less common. For example, you probably know the word baboon, but you probably do not know the word vortex, and you definitely do not know the word epizeuxis. (By the way, a vortex is a swirl of air or fluid, and an epizeuxis is the quick repetition of a word, like "rain, rain, rain.")

BASIC SCIENCE

Research that creates knowledge about how things work.

\section{APPLIED SCIENCE}

Research that uses basic science to find solutions to problems.
We use these measures of behavior to do two types of research. Basic science tells us the basics of how little kids learn. We try to understand what little kids can and cannot do, and we use research findings to form theories of how humans learn. Applied science is different, but related. With applied science, we try to understand how we can help little kids who are behind in learning, or kids who did not grow up with the same opportunities as other kids.

\section{DIFFERENT KIDS' HOMES}

These methods have taught us a lot about what kids know. But to fully understand how kids learn language, we also need to know about their homes and communities, and especially about the language they hear. Do kids hear a lot of language at home or only a little? Do parents say thousands of different words or just a few dozen? Do grownups describe and explain words to kids or do kids have to figure out what words mean? To try to answer these questions, scientists record parents and kids interacting. Then, they spend hours analyzing what was said.

In one important study, researchers went into families' homes once per month and recorded what kids heard and said for 1 hour (the researchers were named Betty Hart and Todd Risley [1], and they published a book about their research in 1995). They started doing this when the babies were only 9 months old, and they kept going to their homes every month until the kids were 3 years old. During this time, kids began to talk, and the scientists plotted every new word 
that the kids said. This plot showed how the kids' vocabularies grew over time, like in Figure 1. They also wrote down all the words and sentences that parents said to their kids. After analyzing these recordings, they found that most kids started speaking around their first birthday, but some kids learned new words much more quickly than other kids did. They also found that kids were better at learning new words if their parents talked to them a lot at home. Kids who heard lots of language-more words, more different words, more questions, more encouraging words, and more words that described things-had bigger vocabularies than kids who did not hear as much language.

One important finding from this study was that kids heard more language if they were from families with more money. Kids from families with very little money did not hear as much language at home. Have you thought about this? You probably know that some families have more money than others, and this affects where a kid lives, what kind of food they get to eat, and how many toys and books they have. But this study showed that the amount of money a family has also affects the experiences kids get to have. Keep in mind that these are just averages and there are always lots of exceptions! Some kids from families with more money do not hear much language at home, and some kids from families with very little money hear lots of language at home. The main point is this: from the time they are babies, some kids get lots of opportunities to play and learn, and other kids get fewer opportunities. Scientists who study the brain know that the things kids experience every day can influence how their brains grow (we think you should read another article in Frontiers for Young Minds, written by Uban et al. [2]). So, if we want to give every kid a fair chance to learn important stuff like language, then we have to give kids the same opportunities starting when they are born.

Scientists want to help, but first they want to find out what kinds of experiences help little kids learn. In one study, scientists tried to figure out how many words kids hear at home each day [3]. All of the kids in the study were from

Different kids learn words at different speeds. In this graph, you can see the number of different words that two different kids could say when they were 1,2 , and 3 years old. The red line shows a kid who learned words very quickly and, by the time she was 3 years old, she could say 1,200 different words. Can you find that point in the graph? The blue line shows another kid who also learned lots of words, but more slowly. By the time she was 3 years old, she could say 600 different words. Can you find that point in the graph?

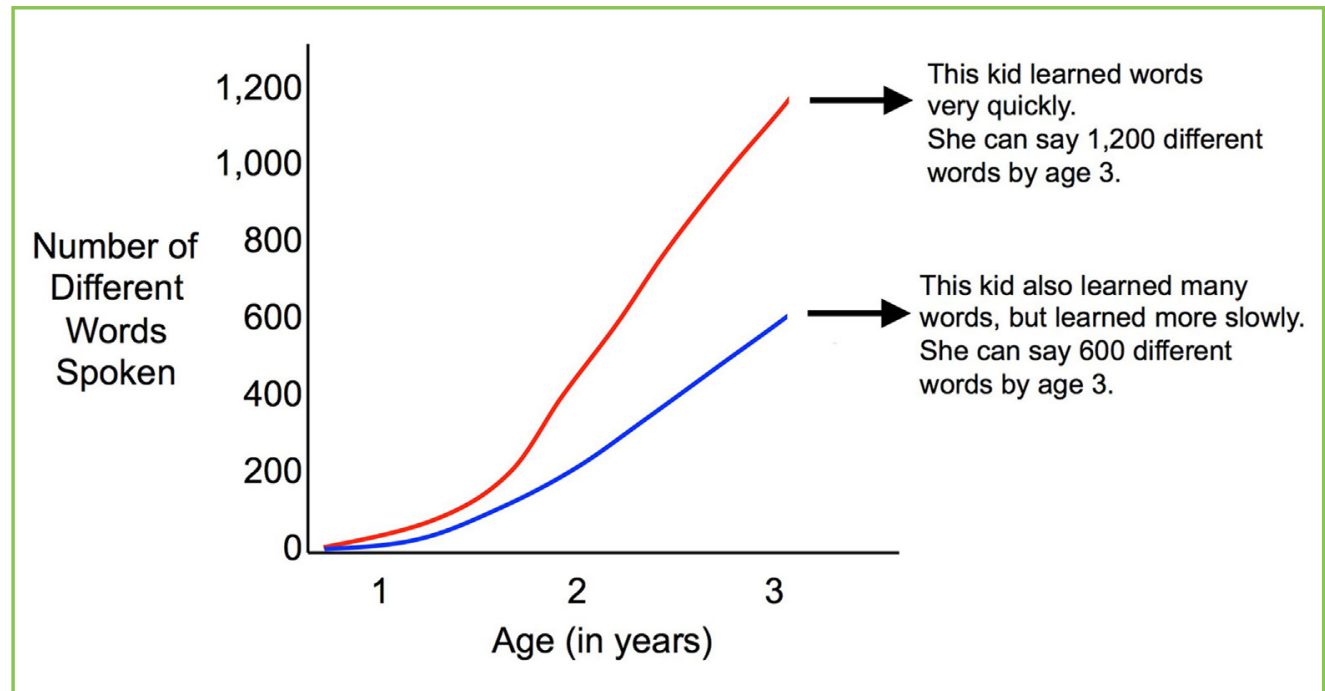


CHILD-DIRECTED SPEECH

Language that grownups and big kids use when talking to little kids.

\section{OVERHEARD SPEECH}

Language that grownups and big kids use when talking to each other, not to little kids.

\section{FIGURE 2}

This graph shows the number of words that different kids heard from grownups in 1 day. Each bar is about one little kid. The green part of each bar shows the number of words that grownups said to that kid in 1 day. The blue part of each bar shows the number of words that kids overheard when grownups were talking to other people. For example, kid 2 heard 2,500 total words in 1 day. 2,000 of those words were directed to her (the part in green), and 500 of those words were overheard (the part in blue). Which kid do you think will learn more: kid 2, 23, or 27?

families with very little money, and the scientists recorded them for an entire day using a little recorder that fits in kids' pockets. Then they used computer software that automatically told them how many words the kids heard. Isn't that interesting? They found that some kids heard 20,000 words in 1 day, while other kids heard 2,500 words in 1 day (Figure 2). Some kids heard lots of language spoken right to them, like when they were talking and playing with their parents, and the scientists called this "child-directed speech." Other kids heard lots of language that was not directed to them, like when their parents were talking to each other or to their brothers and sisters, and the scientists called this "overheard speech." It turns out that the kids who heard lots of language directed to them had bigger vocabularies than the kids who did not hear as much child-directed speech. But kids who heard lots of overheard speech did not have bigger vocabularies. Isn't that weird? It shows that just hearing other people talk or listening to the TV is not enough for little kids to learn language. Talking with little kids-describing what they are looking at, responding to what they say, imitating their sounds-is what matters for learning language from grownups.

There are many reasons why some kids hear more language than others. Some kids do not have any siblings, and some have lots of siblings. Some kids' parents have a lot of time to play with them, and some parents do not have as much time to play. Some kids live with their parents, and some live with other grownups or in group homes. There are many ways in which kids' lives are different, and we still do not completely understand how these differences affect the language they hear. What we do know is that playing and talking are very important for kids to learn language. Kids who get to play and talk a lot are better prepared to start school.

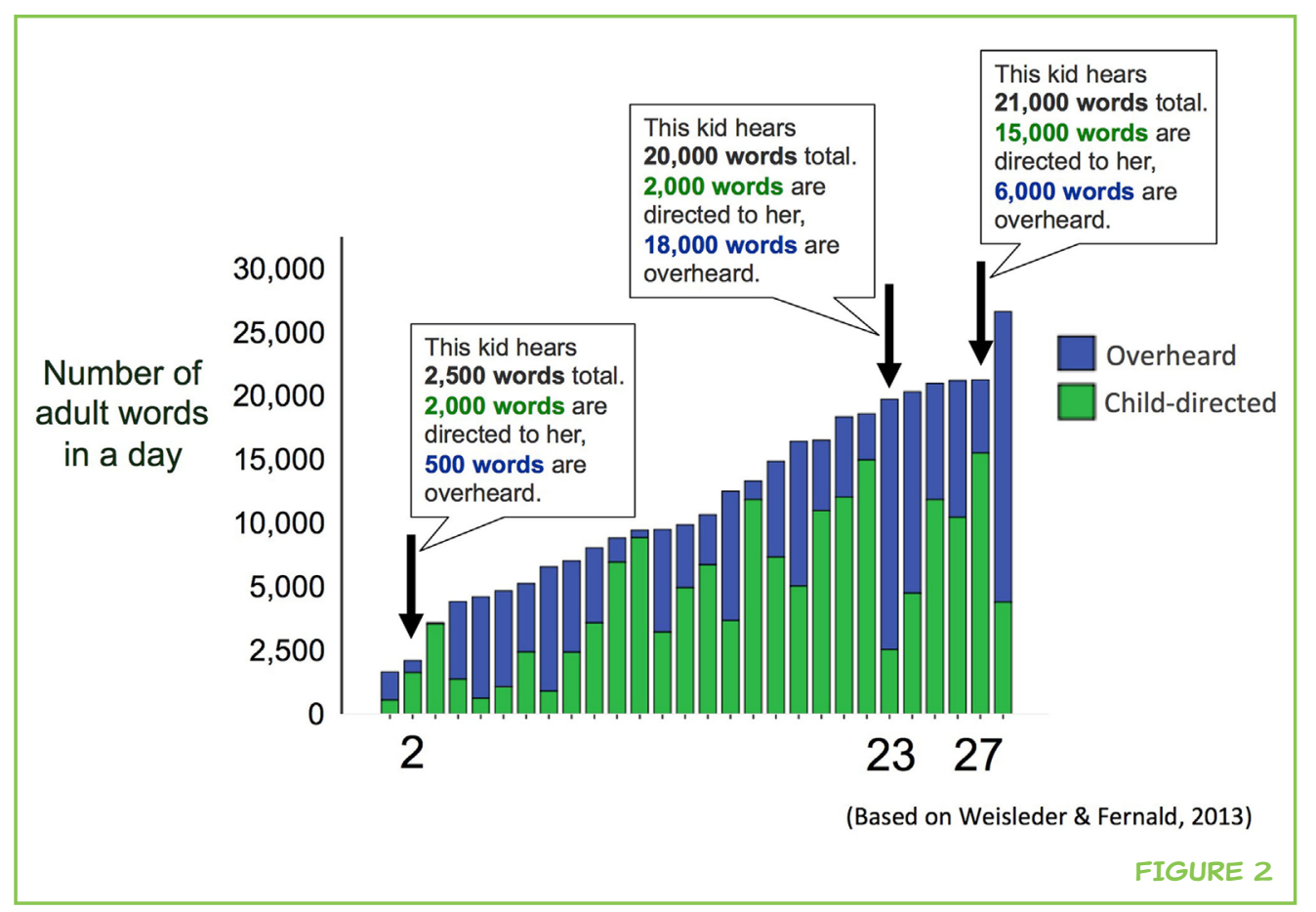




\section{FIGURE 3}

This is a learning cycle. You can see that each arrow points in two directions. Why? Can you figure out how each part of the cycle affects the other parts? Here is one way to describe it. Playing and talking make you better at processing language and that helps you learn words and sentences. The reason this is a cycle is that knowing more language gives you more ways to play and talk with family and friends. So, the cycle continues and helps make kids better and better learners.

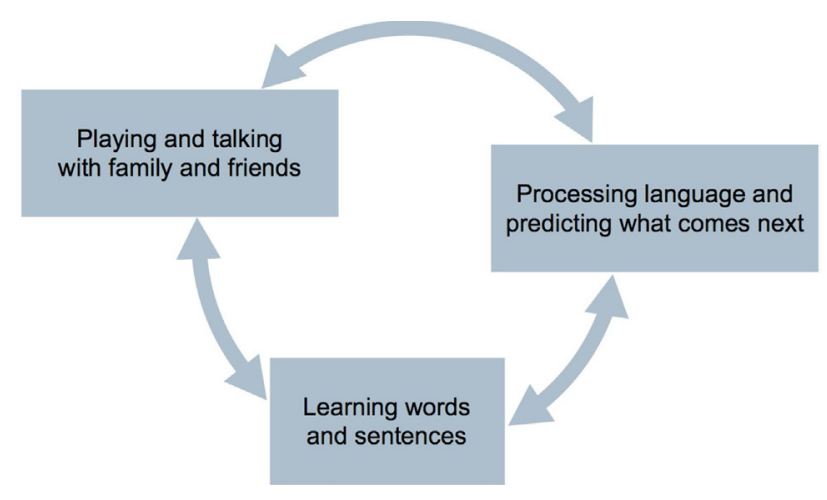

FIGURE 3

\section{GIVING EVERY KID A FAIR CHANCE TO LEARN}

Why does all this matter? In Figure 3, we show you one way to think about this: a learning cycle. This cycle continues as you grow up. You have been a part of this cycle for years. When little kids get a head start with language, they can learn more and more from their parents and teachers. As we talked about in this article, some kids get a lot of chances to play, talk, and learn, and some do not.

Here is some great news. There are lots of people who want to help give every kid a fair chance to learn: parents, teachers, doctors, librarians, social workers, speech therapists, and scientists. All of these people are so helpful. In homes, classrooms, hospitals, universities, churches, and other community centers (like the YMCA and YWCA), grownups are devoted to helping little kids learn.

We want you to know that scientists are working hard to understand how we can best help kids grow up to be happy, healthy, and ready for school. We are doing basic science to understand how little kids learn, and applied science to understand how little kids can thrive. Is there a university near where you live? What is its name? A scientist is probably there right now studying education and learning. Maybe you could work in a lab someday and help us understand how little kids develop and learn.

Remember: each kid is different, and each home is different. How you grew up may be different from the way your friends grew up. Your apartments and houses might look different, but more importantly, the things you do at home are different. These differences matter for how we learn, how we grow up, and who we become. It seems simple, but playing with little kids is really important for helping them learn language. Playing and talking help kids learn more and more, both at home and at school. In just 5 years or so, you might take care of kids as a babysitter or at a summer camp. We hope you remember what you read in this article.

Do you have a parent, teacher, or friend near you right now? Go ask a question, have a conversation, or play a game, and see if you learn something interesting. 


\section{REFERENCES}

1. Hart, B., and Risley, T. R. 1995. Meaningful Differences in the Everyday Experience of Young American Children. Baltimore, MD: Brookes.

2. Uban, K., Herting, M., and Sowell, E. R. 2016. Can money buy you a better brain? What do you think? Front. Young Minds 4:13. doi:10.3389/frym.2016.00013

3. Weisleder, A., and Fernald, A. 2013. Talking to children matters: early language experience strengthens processing and builds vocabulary. Psychol. Sci. 24(11): 2143-52. doi:10.1177/0956797613488145

SUBMITTED: 02 May 2017; ACCEPTED: 24 July 2017;

PUBLISHED ONLINE: 17 August 2017.

EDITED BY: Nadine Gaab, Harvard Medical School, United States

CITATION: Lew-Williams C and Weisleder A (2017) How Do Little Kids Learn Language? Front. Young Minds 5:45. doi:10.3389/frym.2017.00045

CONFLICT OF INTEREST STATEMENT: The authors declare that the research was conducted in the absence of any commercial or financial relationships that could be construed as a potential conflict of interest.

COPYRIGHT @ 2017 Lew-Williams and Weisleder. This is an open-access article distributed under the terms of the Creative Commons Attribution License (CC BY). The use, distribution or reproduction in other forums is permitted, provided the original author(s) or licensor are credited and that the original publication in this journal is cited, in accordance with accepted academic practice. No use, distribution or reproduction is permitted which does not comply with these terms.

\section{REVIEWED BY}

\section{NICK, 12 YEARS OLD}

My name is Nick and I am 12 years old and will be in seventh grade next year. My favorite subjects in school are mathematics and PE. I like playing baseball and soccer and hanging out with my neighbors. I am excited to go to camp this summer!

\section{AUTHORS}

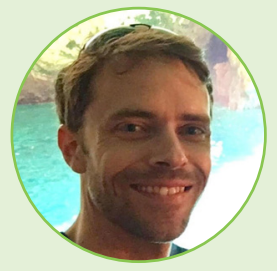

\section{CASEY LEW-WILLIAMS}

I am an Assistant Professor in the Department of Psychology at Princeton University. I work with a group of scientists in a laboratory called the Princeton Baby Lab. We try to understand how babies learn, and we are very interested in studying language. I like my job because I get to test ideas, create knowledge, teach college students, and learn new things every day about child development. *caseylw@princeton.edu 


\section{ADRIANA WEISLEDER}

I am an Assistant Professor in the Department of Pediatrics at New York University School of Medicine. I work with a group of psychologists and pediatricians to try to understand what helps little children grow and develop, and to help all families give these opportunities to their children. I like my job because I get to test ideas, work with little kids, and learn new things that can help give all kids a fair chance. 